\title{
Heat Transfer Analysis and Estimation of Refractory Wear in an Iron Blast Furnace Hearth Using Finite Element Method
}

\author{
Surendra KUMAR \\ Forge Technology Department, National Institute of Foundry and Forge Technology, Ranchi-834 003, India.
}

(Received on March 11, 2005; accepted on May 23, 2005)

\begin{abstract}
The wear of hearth refractory by hot metal penetration and mechanical erosion is the limiting factor in the life of a blast furnace and their control and minimisation result in a direct benefit in an extended campaign. At the same time, it is difficult to directly measure the amount and location of hearth erosion during any campaign. Heat transfer mathematical model is an appropriate tool to quantify the amount of erosion based on the prediction of temperature profile particularly $1150^{\circ} \mathrm{C}$ freeze line isotherm in the hearth.

In the present investigation, an axisymmetric conductive heat transfer model based on finite element method has been formulated and computer software is developed. Using the model and the computer code, temperature profile is predicted in the hearth zone of two different designs of industrial blast furnaces and maximum (worst) hearth wear has been estimated. The erosion pattern is calculated on the basis of worst-case location of $1150^{\circ} \mathrm{C}$ isotherm that can occur during the furnace campaign. Effects of hot metal temperature, cooling conditions and coke-bed states (floating and sitting) on temperature profile and refractory wear are also investigated.
\end{abstract}

KEY WORDS: blast furnace hearth; heat transfer; refractory wear; finite element method.

\section{Introduction}

In order to ensure long campaign life of an iron-making blast furnace without expensive and time-consuming relinings, it is important to carefully monitor the condition of the hearth and to take appropriate measures to control and minimise the degradation of hearth linings and decrease in wall thickness. The hearth refractory lining may be eroded by the penetration of hot metal in the pores of refractory lining, flow of hot metal past the refractory surface, by undergoing some form of chemical reaction with the hot metal and slag or by thermomechanical tension. These processes are abated only by build up of solidified skull material at about $1150^{\circ} \mathrm{C}$ on the refractory surfaces which forms as a result of low hearth wall temperatures or low velocity metal and slag flows in the hearth. $1150^{\circ} \mathrm{C}$ freeze line isotherm corresponds to the maximum hot metal penetration in the hearth linings, since the carbon saturated pig iron cannot exist below this temperature in liquid form. The erosion profile is usually estimated as the most severe location of this isotherm experienced during the furnace campaign. If, in turn, the estimated location of the isotherm falls inside the erosion line, the volume between these two is considered to be filled with skull material. While it is always desirable to keep a thin layer of skull that protects the wall from erosion, at the same time the growth of skull also needs to be controlled in order to avoid decrease in useful hearth capacity.

The erosion of the hearth walls is influenced by several factors, particularly flow of hot metal in the hearth. Metal flow in the hearth doesn't only influence the heat load on the hearth wall and hearth bottom, but also causes erosion due to the hydrodynamic shear stresses particularly at the corner sections. Different flow patterns can exist as a result of the different states of the coke-bed (dead-man): the floating coke-bed and the sitting coke-bed, ${ }^{1)}$ as depicted schematically in Fig. 1. In case of floating coke-bed, there exists a flow channel under the coke-bed while in case of sitting coke-bed, there is no flow channel under the cokebed but there can be a coke-free gutter in the hearth corners. When the sitting coke-bed covers the entire surface area of the hearth bottom, the heat load on the hearth bottom is significantly low in comparison to floating coke-bed. It is difficult to precisely define the conditions for change in the state of the coke-bed which can be influenced by several factors particularly volume of the liquids (metal and slag) in the hearth. Further, it is also complex to estimate the coke-bed voidage which can vary from the tuyere level to

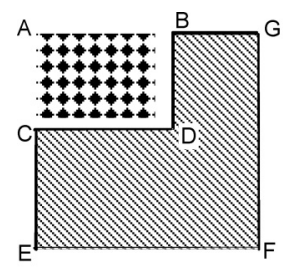

(a)

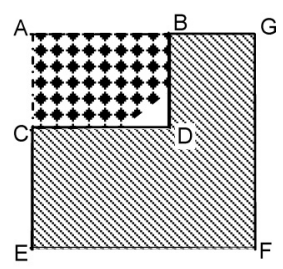

(b)
Fig. 1. Simulation of symmetric half portion of blast furnace hearth with two different states of coke-bed (a) floating and (b) sitting with an annular zone of variable porosity in the corner. 
the lower part of the hearth. Some investigators ${ }^{2,3)}$ have also reported the presence of some low porosity material or low permeability zone beneath the dead man in the hearth, which may be composed of coke fines and deposits.

Due to hostile conditions in the hearth, direct measurements of the remaining hearth lining thickness are difficult during the campaign and operator generally relies on estimates based on indirect measurements such as thermocouple readings. A heat transfer mathematical model is an appropriate tool to quantify the amount of hearth erosion based on the prediction of temperature profile particularly $1150^{\circ} \mathrm{C}$ isotherm in the hearth, and therefore, has been well adopted by several investigators. ${ }^{4-11)}$ In some of these studies, ${ }^{8,9)}$ erosion line and skull profile have been calculated by varying the position of $1150^{\circ} \mathrm{C}$ isotherm and determining the position that gives best fit between the calculated temperature distribution and the temperature measured by thermocouples located in the hearth lining. Using this approach, an accurate and reliable prediction can be achieved if the blast furnace has state-of-art monitoring system consisting of sufficient number of thermocouples in the hearth region. Such monitoring system will also facilitate in calculating cold face boundary conditions, particularly at the walls, on the basis of readings of thermocouple pairs.

Once the prediction of the hearth erosion and skull profile is validated, these findings can also be helpful to interpret the internal state of the furnace hearth which includes hearth coke voidage, state of the dead-man and general flow patterns of the molten iron. ${ }^{12)}$

In the present investigation, an axisymmetric finite element heat transfer model has been formulated to calculate the temperature profile inside the hearth refractories and estimate the maximum (worst) hearth wear, and a computer program is developed based on the model. The model incorporates different types of boundary conditions in terms of prescribed temperature, prescribed heat flux and prescribed convection at the cold faces (side walls and underhearth) as well as hot metal-refractory interface. Two different designs of operating blast furnace hearths are studied for heat transfer analysis and estimation of hearth wear. Systematic study has also been performed to investigate the effects of different parameters such as hot metal temperature, cooling conditions and coke-bed states (floating and sitting). Variation in thermal conductivities of different refractories with temperature is incorporated in the model by using iterative solution method. Maximum hearth erosion is estimated as the most severe location of $1150^{\circ} \mathrm{C}$ isotherm experienced or to be experienced during the campaign. To accomplish this estimation, moving boundary (hot metalrefractory interface) approach is used in which thermal properties of refractory materials is sequentially replaced by that of hot metal (in case of floating coke-bed) or hot metal mixed with coke (in case of sitting coke-bed), depending upon the temperature distribution.. This approach again involves the usage of iteration method in solution procedure. The predicted temperature profile has also been compared with the readings of thermocouples located inside the hearth.

\section{Mathematical Model}

\subsection{Heat Balance Equation}

The heat balance equation in cylindrical co-ordinates $(r, \theta$, z) can be expressed as:

$$
\begin{aligned}
& \rho c_{\mathrm{p}} \frac{\partial T}{\partial t}=\frac{1}{r} \frac{\partial}{\partial r}\left(K_{r} r \frac{\partial T}{\partial r}\right)+\frac{1}{r^{2}} \frac{\partial}{\partial \theta}\left(K_{\theta} \frac{\partial T}{\partial \theta}\right) \\
& +\frac{\partial}{\partial z}\left(K_{z} \frac{\partial T}{\partial z}\right)+q^{\prime \prime \prime}
\end{aligned}
$$

where $\rho$ is density, $c_{\mathrm{p}}$ is specific heat, and $K_{r}, K_{\theta}$ and $K_{z}$ are thermal conductivities in $r, \theta$ and $z$ directions. Since no heat is generated in the hearth lining, the heat generation rate per unit volume, $q^{\prime \prime \prime}$ can be neglected. As there will be only relatively small irregularities in the geometry, material properties and boundary conditions in the angular direction of the hearth, the angular heat conduction is neglected and the above three-dimensional equation is reduced to a twodimensional axisymmetric problem as depicted in Fig. 1. Finally, steady state conditions are assumed to prevail, yielding a steady state formulation as follows:

$$
\frac{1}{r} \frac{\partial}{\partial r}\left(K_{r} r \frac{\partial T}{\partial r}\right)+\frac{\partial}{\partial z}\left(K_{z} \frac{\partial T}{\partial z}\right)=0
$$

With reference to schematic diagram in Fig. 1, boundary conditions at the hot metal-refractory interfaces (CD and $\mathrm{BD})$, side-wall cooling surface (FG) and underhearth cooling surface (EF) may include one or more of the following:

1. Specified temperature acting over surface $S_{t}$ :

$$
T=T^{*}
$$

2. Specified heat flux acting over surface $S_{q}$ :

$$
\{q\}^{\mathrm{T}}\{\eta\}=-q^{*}
$$

3 Specified convection acting over surface $S_{c}$ :

$$
\{q\}^{\mathrm{T}}\{\eta\}=-h\left(T_{\mathrm{a}}-T_{\mathrm{s}}\right)
$$

Where $\{\eta\}$ is the unit outward normal vector on the surface, $h$ and $T_{\mathrm{a}}$ are overall heat transfer coefficient and temperature of the fluid (hot metal or cooling fluid(s)) respectively, and $T_{\mathrm{s}}$ is temperature at the surface. The refractory wall surface at the top of the hearth, BG and the rotational axis CE are always set to be adiabatic (zero heat flux).

\subsection{Finite Element Model}

Using variational principle, the above heat balance equations are, upon finite element discretization, reduced to the form:

$$
[K]\{T\}=\{Q\}
$$

Where $[K]$ is the global heat conduction matrix, $\{T\}$ is the global vector of nodal point temperatures and $\{Q\}$ is the global heat flux vector, and can be calculated as:

$$
[K]=\sum_{e}\left[K^{e}\right] \text { and }\{Q\}=\sum_{e}\left\{Q^{e}\right\} .
$$


where $\left[K^{e}\right]$ is overall element heat conduction matrix and $\left\{Q^{e}\right\}$ is element heat flux vector, and given by

$$
\begin{aligned}
{\left[K^{e}\right]=\int_{V}[B]^{\mathrm{T}}[D][B] d V+\int_{S_{c}} h\left[N^{\mathrm{s}}\right]^{\mathrm{T}}\left[N^{\mathrm{s}}\right] d S_{c} } \\
=2 \pi \iint_{\Gamma^{\prime}}[B]^{\mathrm{T}}[D][B] r d r d z+2 \pi \int_{\Gamma_{c}} h\left[N^{\mathrm{s}}\right]^{\mathrm{T}}\left[N^{\mathrm{s}}\right] r d \Gamma_{c} \\
\left\{Q^{e}\right\}=\int_{S_{q}} q^{*}\left[N^{\mathrm{s}}\right]^{\mathrm{T}} d S_{q}+\int_{S_{c}} h T_{\mathrm{a}}\left[N^{\mathrm{s}}\right]^{\mathrm{T}} d S_{c} \\
=2 \pi \int_{\Gamma_{q}} q^{*}\left[N^{\mathrm{s}}\right]^{\mathrm{T}} r d \Gamma_{q}+2 \pi \int_{\Gamma_{c}} h T_{\mathrm{a}}\left[N^{\mathrm{s}}\right]^{\mathrm{T}} r d \Gamma_{c}
\end{aligned}
$$

Matrix [B] in Eq. (6) is as follows:

$$
[B]=\left[\begin{array}{ll}
\frac{\partial}{\partial r} & \frac{\partial}{\partial z}
\end{array}\right]^{\mathrm{T}}[N]
$$

In above equations, $[N]$ is element interpolation (shape) function matrix and $\left[N^{\mathrm{s}}\right]$ is element surface interpolation function matrix. In the present analysis, two-dimensional four-noded isoparametric quadrilateral element is used, as described in many standard texts on finite element method. Conductivity matrix [D] in Eq. (6) can be represented for two-dimensional axisymmetric analysis as follows:

$$
[D]=\left[\begin{array}{cc}
K_{r} & 0 \\
0 & K_{z}
\end{array}\right]
$$

Different refractory materials in the hearth are modelled by incorporating appropriate thermal conductivity values as function of temperature for each material. Since the thermal conductivity values and, hence coefficients of heat conduction matrix $[K]$ in Eq. (4) are functions of temperature, this global equation is solved iteratively at each load step using frontal solution method until the convergence is established.

\subsection{Estimation of Maximum Hearth Wear}

At the sidewall and bottom of the hearth there is always a balance between erosion of the refractory lining and buildup of the solidified skull, which makes the inner hearth geometry dynamic. Whenever erosion taken place, wornout refractories volume is occupied by hot metal mixed with coke. This process ceases when the temperature of the hot metal at the refractory interfaces approaches to be around $1150^{\circ} \mathrm{C}$ when a solidified layer of iron is formed. Further erosion will take place only when the thickness of the solidified skull layer approaches zero.

In order to model the continuous changes in erosion profile in the long operation of the furnace and to estimate the maximum (worst) hearth wear, a moving boundary (interface) approach is used here. In this iteration method, the interface between the hot metal and refractory is continuously updated in each iteration by changing the refractory thermal conductivity values of the finite elements having temperature between freezing temperature of liquid metal $T_{\mathrm{S}}=$ $1150^{\circ} \mathrm{C}$ and liquid metal temperature $T_{\mathrm{L}}$ (taken to be either $T_{\mathrm{L} 1}=1350^{\circ} \mathrm{C}, T_{\mathrm{L} 2}=1400^{\circ} \mathrm{C}, T_{\mathrm{L} 3}=1450^{\circ} \mathrm{C}$ or $T_{\mathrm{L} 4}=1500^{\circ} \mathrm{C}$ ) to be that of either hot metal (in case of floating coke-bed) or coke mixed with hot metal (in case of sitting coke-bed). This follows because of the assumption that the refractory region with temperature between the above temperature ranges has been worn out by hot metal penetration and occupied by either hot metal or hot metal mixed with coke. If, in the next iteration, temperature of any of these modified elements falls below $T_{\mathrm{S}}$, the original refractory thermal conductivity value of this element is retained. This process is continued till convergence is established and difference in temperature values of all the nodes in the current iteration and previous iteration is within the convergence limit appropriately selected.

Several correlation formulas for the conductivity of packed bed have been proposed in the literature with upper and lower bounds determined by arithmetic and harmonic weighted averages respectively. In the present case, thermal conductivity equation proposed by Maxwell as discussed elsewhere ${ }^{13)}$ has been used which can be given as,

$$
k_{\mathrm{cb}}^{\mathrm{eff}}=k_{\text {iron }}\left[\frac{2 \varepsilon k_{\text {iron }}+(3-2 \varepsilon) k_{\text {coke }}}{(3-\varepsilon) k_{\text {iron }}+\varepsilon k_{\text {coke }}}\right]
$$

The reported value of thermal conductivity of coke is approximately $2 \mathrm{~W} \mathrm{~m}^{-1} \mathrm{~K}^{-1}$ while stagnant thermal conductivity value of hot metal in temperature range of $T_{\mathrm{S}}$ and $T_{\mathrm{L} 4}$ ranges from $28-40 \mathrm{~W} \mathrm{~m}^{-1} \mathrm{~K}^{-1}$. During the analysis, the local thermal conductivity of hot metal with intermediate temperature $T\left(T_{\mathrm{S}}<T<T_{\mathrm{L}}\right)$ was linearly interpolated. In case of sitting coke-bed, the coke-bed porosity $(\varepsilon)$ was assumed to be 0.4 in both the central part and annular zone, and can be used as a tuning parameter.

In the present study, maximum refractory wear has been estimated for both states of coke-bed. It was difficult to accurately estimate the heat load and its distribution on the hot-metal refractory interface for two different states of coke-bed, for which a detail computational flow analysis in porous media of variable porosity must be taken. Therefore, in the present study, hot metal-refractory interfaces CD and BD was assumed to be at constant temperature of hot metal, $T_{\mathrm{L}}$. Alternatively, convective heat transfer boundary condition with an appropriate overall heat transfer coefficient and average temperature can also be prescribed on these interfaces.

\section{Results and Discussion}

Calculation of temperature profile and estimation of maximum hearth wear has been carried out for two different designs of operating blast furnaces in India, which are designated as BF-A and BF-B in our present discussion. BF-A has a hearth inner diameter of $9.7 \mathrm{~m}$ and produces about 3050 tons/d of hot metal at a working volume of approximately $2000 \mathrm{~m}^{3}$. BF-B has hearth inner diameter of $9.2 \mathrm{~m}$ and produces about 2700 tons/d of hot metal at a 


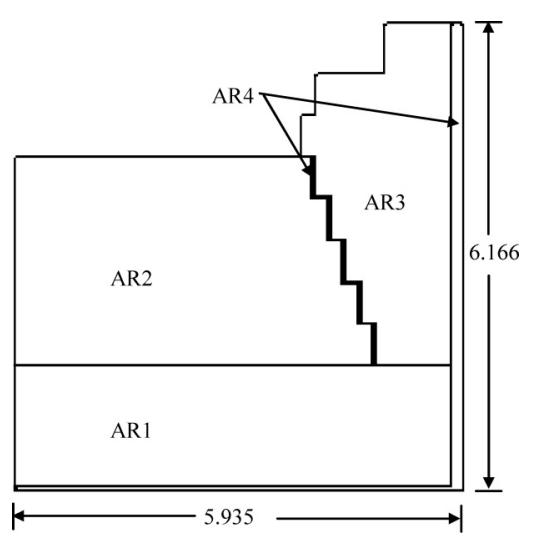

Fig. 2. Schematic diagram of the symmetric half portion of BFA hearth (drawn to scale).

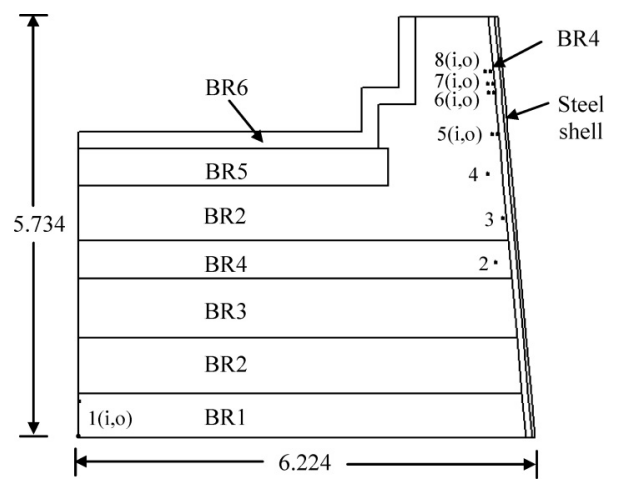

Fig. 3. Schematic diagram of the symmetric half portion of BFB hearth (drawn to scale). Nos. 1 to 8 are thermocouples/ thermocouple pairs (i: inside; o: outside).

Table 1. Thermal conductivities of various materials used in BF-A hearth $\left(\mathrm{W} \mathrm{m}^{-1} \mathrm{~K}^{-1}\right)$.

\begin{tabular}{|ll|}
\hline AR1 & $\mathrm{k}_{\mathrm{z}}=101-0.0577 \mathrm{~T}, \mathrm{k}_{\mathrm{r}}=0.9 \mathrm{k}_{\mathrm{z}}$ \\
AR2 & $\mathrm{k}=0.8+0.00056 \mathrm{~T}$ \\
AR3 & $\mathrm{k}=3.55+0.00179 \mathrm{~T}$ \\
AR4 & $\mathrm{k}=3.15+0.00167 \mathrm{~T}$ \\
$\mathrm{~T}=$ temperature (in ${ }^{\circ} \mathrm{C}$ ) \\
\hline
\end{tabular}

Table 2. Thermal Conductivities of various materials used in BF-B hearth $\left(\mathrm{W} \mathrm{m}^{-1} \mathrm{~K}^{-1}\right)$.

\begin{tabular}{|lr|}
\hline BR1 & \\
BR2 & 116.3 \\
BR3 & 10.0 \\
BR4 & 3.0 \\
BR5 & 9.3 \\
BR6 & 1.5 \\
Steel Shell & 1.1 \\
\hline
\end{tabular}

working volume of approximately $1580 \mathrm{~m}^{3}$. BF-A hearth comprises cast iron stave cooling by water at the side-walls and underhearth air cooling while BF-B utilises water spray cooling at the side-walls and underhearth water cooling. Figures $\mathbf{2}$ and $\mathbf{3}$ show schematic sketches and necessary dimensions (in meter) of the symmetric half portion of the two hearths along with different materials used. The refractories are denoted in coded form because of some plant restraint. The thermal conductivities of these materials for the two hearths are presented in Tables $\mathbf{1}$ and $\mathbf{2}$ respectively.

\subsection{Temperature Profile}

First, heat transfer in different refractories of hearth zone (upto the height near the taphole) was studied for the initial

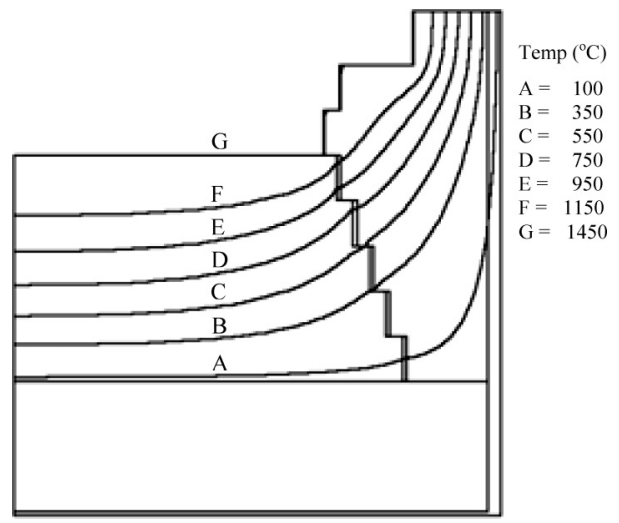

Fig. 4. Temperature profile in different refractories of hearth zone in initial design of BF-A.

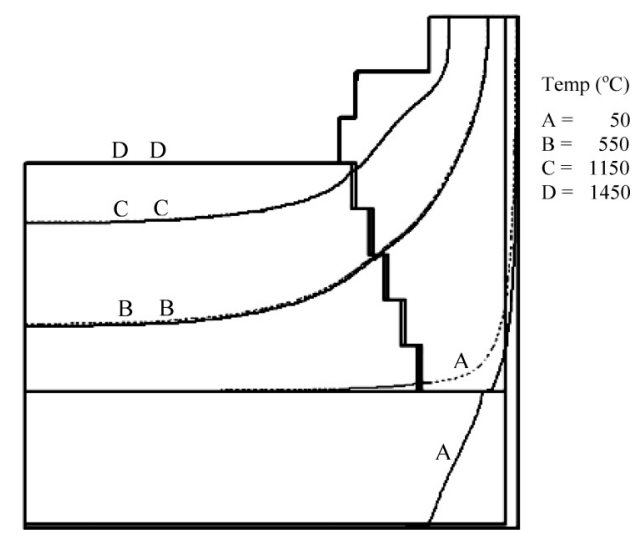

Fig. 5. Effect of cooling conditions (Case $1(-)$ : $T_{\mathrm{w}}=30^{\circ} \mathrm{C}$, $T_{\mathrm{a}}=35^{\circ} \mathrm{C}$ and $h_{\mathrm{w}}=300 \mathrm{~W} \mathrm{~m}^{-2} \mathrm{~K}^{-1}, h_{\mathrm{a}}=10 \mathrm{~W} \mathrm{~m}^{-2} \mathrm{~K}^{-1}$, and Case 2 (……): $T_{\mathrm{w}}=15^{\circ} \mathrm{C}, T_{\mathrm{a}}=20^{\circ} \mathrm{C}$ and $h_{\mathrm{w}}=$ $\left.3000 \mathrm{~W} \mathrm{~m}^{-2} \mathrm{~K}^{-1}, h_{\mathrm{a}}=100 \mathrm{~W} \mathrm{~m}^{-2} \mathrm{~K}^{-1}\right)$ on temperature profile inside the hearth of BF-A.

designs of the blast furnaces A and B.

\subsubsection{Blast Furnace A}

Hot metal-refractory interfaces CD and BD (Fig. 1) were set at constant temperature of hot metal (Eq. 3(a)) taken to be $1450^{\circ} \mathrm{C}$. Convective boundary conditions were specified at the side-wall surface FG and bottom surface EF (Fig. 1) by taking in plant data for average temperatures $\left(T_{\mathrm{w}}=30^{\circ} \mathrm{C}\right.$, $T_{\mathrm{a}}=35^{\circ} \mathrm{C}$ ) and approximate convective heat transfer coefficients $\left(h_{\mathrm{w}}=300 \mathrm{~W} \mathrm{~m}^{-2} \mathrm{~K}^{-1}, h_{\mathrm{a}}=10 \mathrm{~W} \mathrm{~m}^{-2} \mathrm{~K}^{-1}\right)$ for the cooling water and air respectively. The refractory wall surface at the top of the hearth, BG and the symmetry line CE were set to be adiabatic (zero heat flux). The calculated temperature profile (in ${ }^{\circ} \mathrm{C}$ ) including $1150^{\circ} \mathrm{C}$ isotherm is shown in Fig. 4. A different set of data $\left(T_{\mathrm{w}}=15^{\circ} \mathrm{C}, T_{\mathrm{a}}=\right.$ $20^{\circ} \mathrm{C}$ and $h_{\mathrm{w}}=3000 \mathrm{~W} \mathrm{~m}^{-2} \mathrm{~K}^{-1}, h_{\mathrm{a}}=100 \mathrm{~W} \mathrm{~m}^{-2} \mathrm{~K}^{-1}$ ) was also taken to study the effect of cooling conditions and it was observed that change in cold face boundary conditions had negligible effect on the position of $1150^{\circ} \mathrm{C}$ isotherm in this case as depicted in Fig. 5. However, significant effect of hot metal temperature at the hot metal-refractory interfaces was observed as shown in Fig. 6 which depicts the $1150^{\circ} \mathrm{C}$ isotherms calculated for two different hot metal temperatures $1400^{\circ} \mathrm{C}$ and $1500^{\circ} \mathrm{C}$.

\subsubsection{Blast Furnace B}

Convective boundary conditions were specified at the 


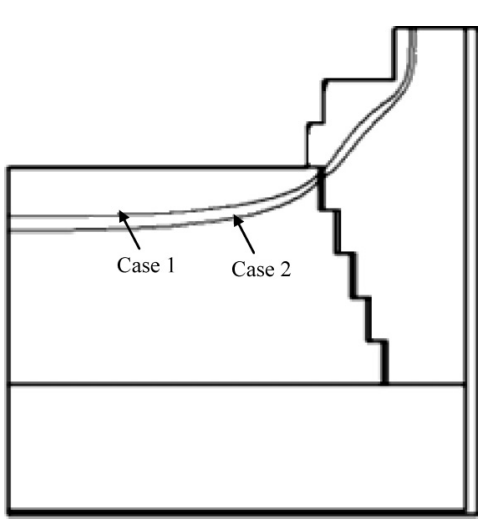

Fig. 6. Effect of hot metal temperature (Case 1: $1400^{\circ} \mathrm{C}$ and Case $2: 1500^{\circ} \mathrm{C}$ ) at the refractory interface on the position of $1150^{\circ} \mathrm{C}$ in the hearth of BF-A.

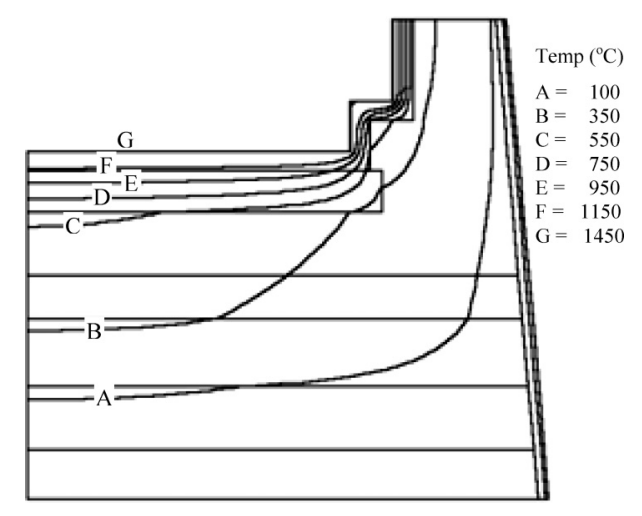

Fig. 7. Temperature profile in different refractories of hearth zone in initial design of BF-B.

side-wall surface FG and bottom surface EF (Fig. 1) by taking in plant data for average temperature $\left(T_{\mathrm{w}}=32^{\circ} \mathrm{C}\right)$ and approximate convective heat transfer coefficient $\left(h_{\mathrm{w}}=\right.$ $300 \mathrm{~W} \mathrm{~m}^{-2} \mathrm{~K}^{-1}$ ) for the cooling water. Since the appropriate convective heat transfer coefficients of cooling water for the two different cooling systems could not be calculated, these data were assumed to be same for both the systems. All other boundary conditions were kept same as BF-A. The calculated temperature profile (in ${ }^{\circ} \mathrm{C}$ ) including $1150^{\circ} \mathrm{C}$ isotherm is shown in Fig. 7. From the result, it can be seen that several isotherms are concentrated towards the upper portion of the hearth. This can be attributed to very low conductivity value of the protective layer material (BR6) used in the region which was taken into consideration in the analysis of this furnace.

\subsection{Maximum Hearth Wear}

Maximum hearth wear was estimated using the methodology described in Section 2.3 for both BF-A and BF-B.

\subsubsection{Blast Furnace A}

Convective boundary conditions were specified at the side-wall surface FG and bottom surface EF (Fig. 1) by taking in two sets of data (a) $T_{\mathrm{w}}=30^{\circ} \mathrm{C}, T_{\mathrm{a}}=35^{\circ} \mathrm{C}, h_{\mathrm{w}}=$ $300 \mathrm{~W} \mathrm{~m}^{-2} \mathrm{~K}^{-1}, \quad h_{\mathrm{a}}=10 \mathrm{~W} \mathrm{~m}^{-2} \mathrm{~K}^{-1}$ and (b) $T_{\mathrm{w}}=15^{\circ} \mathrm{C}$, $T_{\mathrm{a}}=20^{\circ} \mathrm{C}$ and $h_{\mathrm{w}}=3000 \mathrm{~W} \mathrm{~m}^{-2} \mathrm{~K}^{-1}, h_{\mathrm{a}}=100 \mathrm{~W} \mathrm{~m}^{-2} \mathrm{~K}^{-1}$. Hearth wear was predicted for both floating and sitting states of coke-bed. In both coke-bed states, the hot metalrefractory interfaces $\mathrm{CD}$ and $\mathrm{BD}$ (Fig. 1) were set to be at

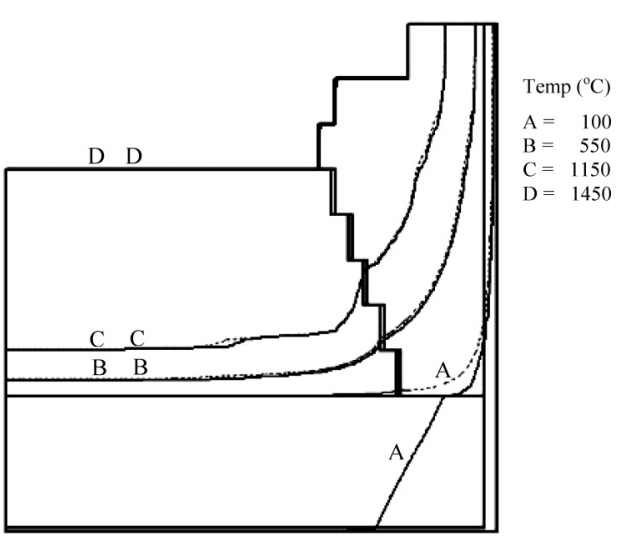

Fig. 8. Effect of cooling conditions (Case $1(-)$ : $T_{\mathrm{w}}=30^{\circ} \mathrm{C}$, $T_{\mathrm{a}}=35^{\circ} \mathrm{C}$ and $h_{\mathrm{w}}=300 \mathrm{~W} \mathrm{~m}^{-2} \mathrm{~K}^{-1}, h_{\mathrm{a}}=10 \mathrm{~W} \mathrm{~m}^{-2} \mathrm{~K}^{-1}$, and Case 2 (…....): $T_{\mathrm{w}}=15^{\circ} \mathrm{C}, T_{\mathrm{a}}=20^{\circ} \mathrm{C}$ and $h_{\mathrm{w}}=$ $3000 \mathrm{~W} \mathrm{~m}^{-2} \mathrm{~K}^{-1}, h_{\mathrm{a}}=100 \mathrm{~W} \mathrm{~m}^{-2} \mathrm{~K}^{-1}$ ) on worst-case positions of different isotherms including $1150^{\circ} \mathrm{C}$ corresponding to maximum erosion profile in the hearth of BF-A (floating coke-bed).

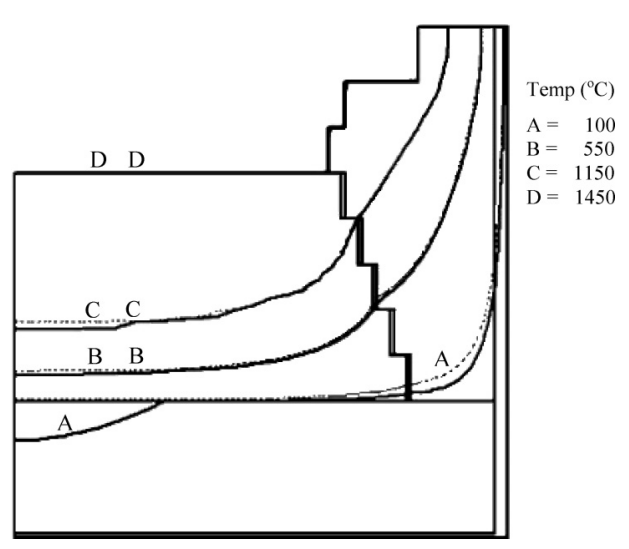

Fig. 9. Effect of cooling conditions (Case $1(-)$ : $T_{\mathrm{w}}=30^{\circ} \mathrm{C}$, $T_{\mathrm{a}}=35^{\circ} \mathrm{C}$ and $h_{\mathrm{w}}=300 \mathrm{~W} \mathrm{~m}^{-2} \mathrm{~K}^{-1}, h_{\mathrm{a}}=10 \mathrm{~W} \mathrm{~m}^{-2} \mathrm{~K}^{-1}$, and Case 2 (……) : $T_{\mathrm{w}}=15^{\circ} \mathrm{C}, T_{\mathrm{a}}=20^{\circ} \mathrm{C}$ and $h_{\mathrm{w}}=$ $3000 \mathrm{~W} \mathrm{~m}^{-2} \mathrm{~K}^{-1}, h_{\mathrm{a}}=100 \mathrm{~W} \mathrm{~m}^{-2} \mathrm{~K}^{-1}$ ) on worst-case positions of different isotherms including $1150^{\circ} \mathrm{C}$ corresponding to maximum erosion profile in the hearth of BF-A (sitting coke-bed).

constant temperature of hot metal taken to be $1450^{\circ} \mathrm{C}$. Worst case locations of different isotherms including $1150^{\circ} \mathrm{C}$ which corresponds to the maximum hearth wear, predicted using the model are shown in Figs. 8 and 9 for the two states of coke-bed. It can be seen that two different cold-face cooling parameters considered here have negligible effect on the maximum hearth wear for both coke-bed states. It is apparent from the figures that for the same prescribed hot metal temperature, the wear pattern predicted in case of floating coke-bed is more than that predicted in case of sitting coke-bed. The reason is that the worn-out refractory region occupied by hot metal mixed with coke in case of sitting coke-bed has much more thermal resistance than the region occupied by hot metal alone in case of floating coke-bed.

\subsubsection{Blast Furnace B}

In this case, temperature boundary conditions based on thermocouples readings were specified at the cold faces (side-walls and bottom) of the hearth. BF-B consists of 


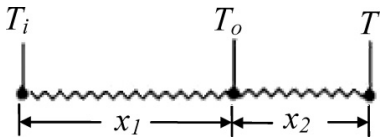

Fig. 10. Thermocouple pair used in calculating side-wall temperature.

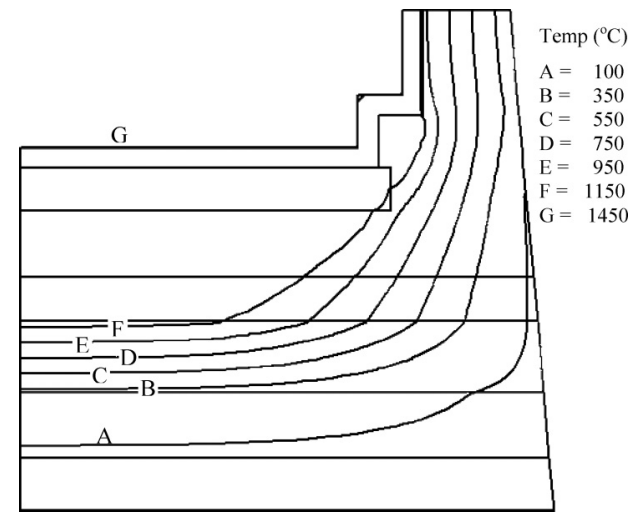

Fig. 11. Worst-case positions of different isotherms including $1150^{\circ} \mathrm{C}$ corresponding to maximum erosion profile in the hearth of BF-B (floating coke-bed).

about 50 thermocouples (TCs) around the hearth zone. Thermocouples readings (over a period of one year) were observed to have a periodic fluctuations which can be attributed to the seasonal fluctuation in cooling fluid temperature, amount of liquid in the hearth and movement of cokemass. Therefore, time-averages of different temperature measurements were used. The readings were also averaged with respect to angular position around the hearth for the thermocouples located at the same height and radial position (insertion into the refractories).

Readings of thermocouple pairs were used in calculating temperature at the side-wall locations in the vicinity of these pairs (Fig. 10) using the equation:

$$
T=T_{\mathrm{o}}-\frac{x_{2}}{x_{1}}\left(T_{\mathrm{i}}-T_{\mathrm{o}}\right)
$$

In Eq. (9), $T_{\mathrm{i}}$ and $T_{\mathrm{o}}$ are the readings of inner and outer thermocouples. At boundary locations away from the thermocouple pairs, nodal temperatures were calculated using linear interpolation based on readings of adjacent pairs. The hearth bottom temperature was taken to be that of cooling fluid. In case of floating coke-bed, the hot metal-refractory interfaces were set to be at constant temperature of hot metal taken to be $1450^{\circ} \mathrm{C}$, while a slightly lower temperature $\left(1400^{\circ} \mathrm{C}\right)$ was specified in case of sitting coke-bed. Figures 11 and 12 depict worst case locations of different isotherms including $1150^{\circ} \mathrm{C}$ which corresponds to the maximum hearth wear, for two coke-bed states.

In order to study the effect of hot metal temperature on the erosion profile, three different cases were considered for both coke-beds by taking hot metal temperature to be $1400^{\circ} \mathrm{C}, 1450^{\circ} \mathrm{C}$ and $1500^{\circ} \mathrm{C}$ in case of floating coke-bed and $1350^{\circ} \mathrm{C}, 1400^{\circ} \mathrm{C}$ and $1450^{\circ} \mathrm{C}$ in case of sitting cokebed. Predicted worst-case positions of $1150^{\circ} \mathrm{C}$ corresponding to maximum wear have been presented in Figs. 13 and 14 for the two beds.

Owing to the same reasons discussed earlier in case of

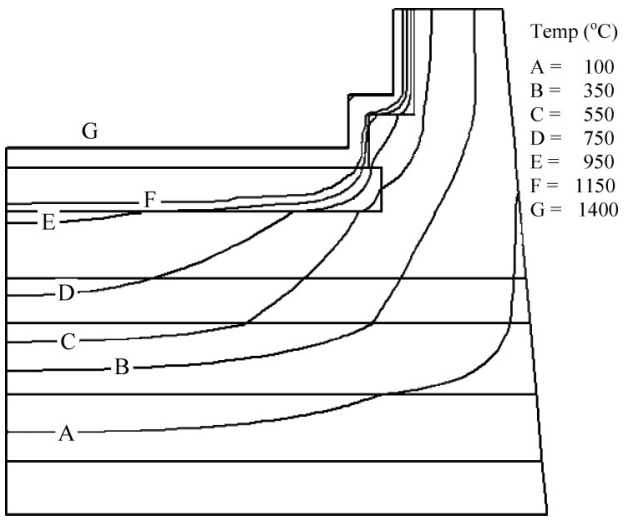

Fig. 12. Worst-case positions of different isotherms including $1150^{\circ} \mathrm{C}$ corresponding to maximum erosion profile in the hearth of BF-B (sitting coke-bed).

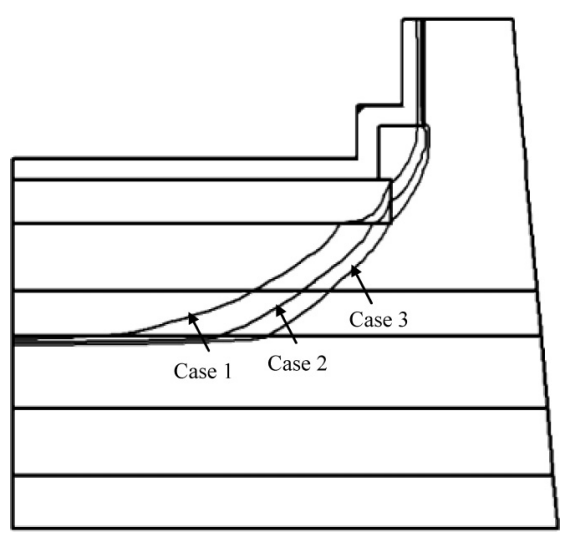

Fig. 13. Effect of hot metal temperature (Case 1: $1400^{\circ} \mathrm{C}$, Case 2: $1450^{\circ} \mathrm{C}$ and Case $3: 1500^{\circ} \mathrm{C}$ ) at the refractory interface on worst-case position of $1150^{\circ} \mathrm{C}$ in the hearth of BF-B (floating coke-bed).

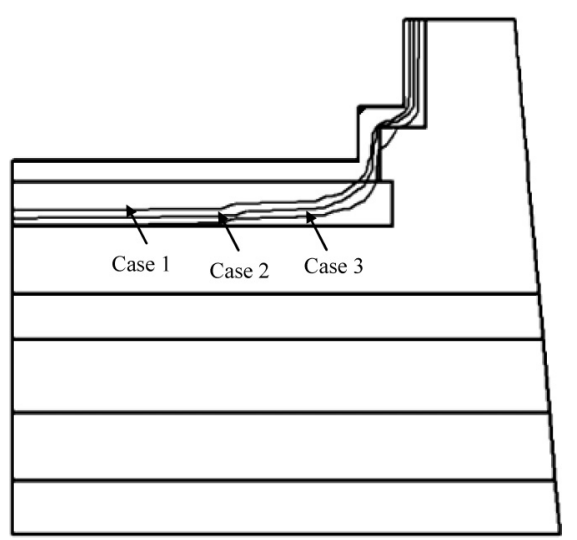

Fig. 14. Effect of hot metal temperature (Case 1: $1350^{\circ} \mathrm{C}$, Case 2: $1400^{\circ} \mathrm{C}$ and Case $3: 1450^{\circ} \mathrm{C}$ ) at the refractory interface on worst-case position of $1150^{\circ} \mathrm{C}$ in the hearth of BF-B (sitting coke-bed).

blast furnace A, significant difference can be observed here also between wear patterns predicted for the two coke-bed states with prescribed hot metal temperature being the same. In general, there occurs frequent change in state of coke mass in the hearth from floating to sitting and viceversa. Therefore, the wear profile predicted in case of floating coke-bed can be considered to be upper bound in this case. 
Table 3. Model predictions of temperatures $v s$. plant observations.

\begin{tabular}{|c|c|c|c|c|c|c|c|c|c|}
\hline \multirow{3}{*}{$\begin{array}{l}\text { TC } \\
\text { No. }\end{array}$} & \multirow{3}{*}{$\begin{array}{l}\text { Height } \\
\text { (m) }\end{array}$} & \multirow{3}{*}{$\begin{array}{l}\text { Insertion } \\
\text { in BR2 } \\
(\mathrm{mm})\end{array}$} & \multirow{3}{*}{$\begin{array}{l}\text { TC } \\
\text { Reading } \\
\left({ }^{\circ} \mathrm{C}\right)\end{array}$} & \multicolumn{6}{|c|}{ Model Predicted Temperature $\left({ }^{\circ} \mathrm{C}\right)$} \\
\hline & & & & \multicolumn{3}{|c|}{ Floating Coke-Bed } & \multicolumn{3}{|c|}{ Sitting Coke-Bed } \\
\hline & & & & Case 1 & Case 2 & Case 3 & Case 1 & Case 2 & Case 3 \\
\hline 4 & 3.594 & 200 & 186 & 196 & 213 & 223 & 149 & 155 & 169 \\
\hline 5 (i) & 4.134 & 95 & 256 & 251 & 264 & 270 & 216 & 221 & 233 \\
\hline 6 (i) & 4.694 & 95 & 308 & 302 & 317 & 323 & 270 & 276 & 289 \\
\hline 7 (i) & 4.794 & 95 & 290 & 295 & 311 & 316 & 264 & 271 & 284 \\
\hline 8 (i) & 4.994 & 110 & 273 & 286 & 302 & 306 & 257 & 264 & 276 \\
\hline
\end{tabular}

The wear profile predicted here is two-dimensional axisymmetric and based on the readings of thermocouples averaged with respect to angular positions around the hearth. However, as discussed earlier, some deviations exist in readings of thermocouples located at same height and radial position but different angular positions. In order to account for variations in the angular direction, two-dimensional erosion profiles can be calculated at some selected angular positions by prescribing the cold face temperature boundary conditions based on the readings of thermocouple pairs at these positions. By this way, a three-dimensional erosion profile can be estimated.

\subsection{Comparison of Model Predictions with Measured Data}

Since the readings of thermocouple pairs located near the cold faces were themselves used in determining the cold face boundary conditions for the estimation of maximum refractory wear above, it was not proper to compare the model prediction for temperatures at these locations with the plant data particularly for outside thermocouples (closer to the cold faces). However, a comparison can be made between the model predictions with temperature data for inside thermocouples. Table 3 shows the temperature predictions for the various cases considered along with the average measured thermocouple readings.

It can be observed from the table that most of measured temperature data lie between predicted values for sitting bed and floating bed. This leads to the conclusion that temperature values predicted in the case of floating coke-bed can be considered to be the worst situation values.

It is to be mentioned here that an appropriate validation of the current model would be a comparison of the estimated wear profile with the observed one during the post mortem of the blast furnace when it is blown out for relining.

\section{Conclusions}

An axisymmetric conductive heat transfer model based on finite element method has been formulated and computer software is developed. Using the model and the computer code, temperature profile has been calculated for two different designs of operating blast furnaces and maximum hearth wear corresponding to worst location of $1150^{\circ} \mathrm{C}$ isotherm that can be experienced during the operation, is predicted. Moving hot metal-refractory interface is used to calculate hearth erosion in which thermal properties of refractory materials is sequentially replaced by that of hot metal mixed with coke depending upon the temperature distribution. Effects of heat load at the hot metal-refractory interface, cooling conditions at the side walls and at the bottom of the hearth, and coke-bed state (sitting or floating) on the hearth wear have been investigated. Efforts are now in progress to study the influence of flow condition of hot metal in the hearth on the refractory wear.

\section{Acknowledgements}

Considerable portion of this research work was carried out by the author during his past tenure at National Metallurgical Laboratory (NML) Jamshedpur, India, as a part of sponsored project by Ministry of Steel, Government of India. The author is grateful to Prof. P Ramachandra Rao, Past Director, Prof. SP Mehrotra, Director, NML Jamshedpur and Dr. RP Goel, Project Coordinator for continuous guidance and support. The plant data provided are also thankfully acknowledged.

\section{REFERENCES}

1) Y. Omori: Blast Furnace Phenomena and Modelling, ISIJ, Tokyo, (1987), 396.

2) M. J. Venturini. J. P. Bolsigner, J. Iezzi and D. Sert: Proc. of 57th Ironmaking Conf., ISS, Warrendale, PA, (1998), 615.

3) K. Takeda, S. Watakabe, Y. Sawa, H. Itaya, T. Kawai and T. Matsumoto: Proc. of 58th Ironmaking Conf., ISS, Warrendale, PA, (1999), 657.

4) S. J. Gdula, R. Bialecki, K. Kurpisz, A. Nowak and A. Sucheta: Trans. Iron Steel Inst. Jpn., 25 (1985), 380.

5) K. Kurpisz: Trans. Iron Steel Inst. Jpn., 28 (1988), 926.

6) S. P. Mehrotra and Y. C. Nand: ISIJ Int., 33 (1993), 839.

7) T. Inada, K. Takatani, M. Miyahara, S. Wakabaysi, T. Yamamoto, A. Kasai and K. Takata: Proc. of 58th Ironmaking Conf., ISS, Warrendale, PA, (1999), 633.

8) A. Ferstl, G. Kolb and G. Brunnbauer: Proc. of 58th Ironmaking Conf., ISS, Warrendale, PA, (1999), 713.

9) J. Torrkulla and H. Saxen: ISIJ Int., 40 (2000), 438,

10) S. Kumar, K. M. Godiwalla and S. P. Mehrotra: Proc. of Asia Steel Int. Conf., IIM, Jamshedpur, India, (2003), 1.f.4.1.

11) R. van Laar, E. van Stein Callenfels and M. Geerdes: Proc. of Int. Tech. Conf., ISS, Warrendale, PA, (2003), 1079.

12) J. Brannbacka and H. Saxen: ISIJ Int., 43 (2003), 1519.

13) R. L. Hamilton and O. K. Crosser: Ind. Eng. Chem. Fundam., 1 (1962), 187. 